\title{
Kernos
}

Revue internationale et pluridisciplinaire de religion grecque antique

$27 \mid 2014$

Varia

\section{Beat NÄF, Testimonia Alt-Paphos}

\section{Vinciane Pirenne-Delforge}

\section{(2) OpenEdition}

\section{Journals}

Édition électronique

URL : http://journals.openedition.org/kernos/2256

DOI : 10.4000/kernos.2256

ISSN : 2034-7871

Éditeur

Centre international d'étude de la religion grecque antique

Édition imprimée

Date de publication : 1 novembre 2014

Pagination : 490-491

ISBN : 978-2-87562-055-2

ISSN : 0776-3824

\section{Référence électronique}

Vinciane Pirenne-Delforge, «Beat NÄF, Testimonia Alt-Paphos », Kernos [En ligne], 27 | 2014, mis en ligne le 12 novembre 2014, consulté le 22 septembre 2020. URL : http://journals.openedition.org/kernos/ 2256 ; DOI : https://doi.org/10.4000/kernos.2256

Ce document a été généré automatiquement le 22 septembre 2020.

Kernos 


\title{
Beat NÄF, Testimonia Alt-Paphos
}

\author{
Vinciane Pirenne-Delforge
}

\section{RÉFÉRENCE}

Beat NÄF, Testimonia Alt-Paphos, Mainz, Philipp von Zabern, 2013. 1 vol. $23 \times 31,5 \mathrm{~cm}$, xviii+116 p. (Ausgrabungen in Alt-Paphos auf Cypren, 8). ISBN : 978-3-8053-4579-8.

1 Ce volume s'inscrit dans la série qui publie les fouilles dirigées par Franz Georg Maier à Palaipaphos dans l'île de Chypre depuis les années 1950. L'ouvrage reprend de manière systématique les testimonia littéraires évoquant Paphos, depuis la période archaïque jusqu'au tout début $\mathrm{du} \mathrm{xx}^{\mathrm{e}}$ siècle. Chaque notice comprend l'auteur et le titre de l'œuvre, sa datation et le contexte du passage, la référence complète, le texte original, une traduction allemande, quelques éléments bibliographiques et un commentaire éventuel. Ces notices sont essentiellement réparties dans le chapitre III, qui regroupe chronologiquement les testimonia antiques (signalons que les scholiastes et commentaires suivent directement l'œuvre commentée, ce qui rompt la chronologie mais satisfait à la cohérence du propos), dans le chapitre IV, qui regroupe les mentions de Paphos depuis le moyen âge jusqu'au XVIII ${ }^{\mathrm{e}}$ siècle, et dans le chapitre V qui voit se succéder les voyageurs, chercheurs et archéologues qui se sont arrêtés sur le site, plus ou moins longtemps selon les cas, depuis le XVIII ${ }^{\mathrm{e}}$ siècle jusqu'aux évocations de Paphos par Max Ohnefalsch-Richter ou John Myres. Les chapitres précédents (I et II) reprennent respectivement des notices sur la géographie du lieu (I) et les Paphiens historiques, tout autant que certains aspects des mythes locaux (II). Dans cette dernière catégorie, on trouve, par ordre alphabétique, les protagonistes divins et héroïques associés au site (par ex. Adonis, Agapenor, Aphrodite, Kinyras...) tout autant que des aspects du culte (par ex. Opfer, Orakel, Pflanzen- und Tierwelt, Priester...). Les notices des sources invoquées à cet endroit peuvent être consultées dans les chapitres suivants.

Il s'agit d'un outil de travail soigneusement conçu et impeccablement édité. Il rendra d'incontestables services à ceux qu'intéressent le site de Paphos et le sanctuaire de sa «souveraine ", en qui les Grecs ont vu très tôt une Aphrodite. Pour compléter le 
tableau de la documentation antique, il convient également de se reporter au volume IV (1986) des Ausgrabungen, dû à O. Masson et T.B. Mitford sur Les inscriptions syllabiques de Kouklia-Paphos, et d'attendre le volume d'A. Kolb, annoncé dans la même série, sur les inscriptions alphabétiques.

\section{AUTEURS}

VINCIANE PIRENNE-DELFORGE

F.R.S.-FNRS - Université de Liège 